\title{
Níveis de cálcio na manutenção da qualidade interna de ovos de codornas japonesas após armazenamento
}

\author{
Levels of calcium in the maintenance of internal egg quality of Japanese quails after \\ storage
}

\author{
SOUZA, Daniele Santos de ${ }^{1 *}$; SILVA FILHO, Carlos Alberto da ${ }^{2}$; PINHO, Thiers \\ Pascoal $^{2}$; AZEVEDO, Verônica Mendes de ${ }^{2}$; OLIVEIRA, Sérgio Muniz de ${ }^{2}$; \\ CALIXTO, Lígia Fátima Lima ${ }^{3}$
}

\author{
${ }^{1}$ Universidade Federal Rural do Rio de Janeiro, Instituto de Zootecnia, Programa de Pós-Graduação em \\ Zootecnia, Seropédica, Rio de Janeiro, Brasil. Bolsista Capes; \\ ${ }^{2}$ Universidade Federal Rural do Rio de Janeiro, Instituto de Zootecnia, Curso de Graduação em \\ Zootecnia, Seropédica, Rio de Janeiro, Brasil; \\ ${ }^{3}$ Universidade Federal Rural do Rio de Janeiro, Docente. Instituto de Zootecnia, Departamento de \\ Produção Animal, Seropédica, Rio de Janeiro, Brasil. \\ *Endereço para correspondência: danyssz@gmail.com
}

\section{RESUMO}

O objetivo com este estudo foi avaliar a influência de níveis crescentes de cálcio na dieta na melhoria da qualidade externa e consequente manutenção da qualidade interna de ovos de codornas em final de produção, armazenados por 14 dias em temperatura ambiente. Foram utilizadas 400 codornas japonesas com 46 a 58 semanas de idade, distribuídas em um delineamento inteiramente casualizado onde foram testados cinco níveis de cálcio: $2,95 \%$, $3,25 \%, \quad 3,55 \%, \quad 3,85 \%, \quad 4,15 \%$ Ca. Os parâmetros avaliados foram: espessura de casca, peso e porcentagem de casca, porcentagem de gema, porcentagem de albúmen, peso médio dos ovos e a perda de peso de ovos de codornas. Os resultados mostraram que os níveis crescentes de cálcio promoveram após o período de armazenamento $(\mathrm{P}<0,05)$ melhor espessura da casca, maior porcentagem de gema, menor porcentagem de albúmen e aumento no peso dos ovos sem influenciar significativamente o peso, porcentagem de casca e a perda de peso de ovos de codornas após o armazenamento em temperatura ambiente por 14 dias. Concluiu-se que a inclusão de níveis crescentes de cálcio na ração foi eficiente na manutenção da qualidade interna de ovos de codornas japonesas após o armazenamento em temperatura ambiente por 14 dias.

Palavras-chave: Coturnix coturnix japonica, estocagem, qualidade da casca

\section{SUMMARY}

The objective of this study was to evaluate the influence of increasing levels of dietary calcium in improving the external quality and consequent maintenance of internal quality quail eggs at the end of production, stored for 14 days at room temperature. 400 Japanese quails with 46-58 weeks of age, distributed in a completely randomized design where they were tested five calcium levels: $2.95 \%, 3.25 \%, 3.55 \%, 3.85 \%$, $4.15 \% \mathrm{Ca}$. The parameters evaluated were: shell thickness, weight and percentage of shell, percentage of yolk, albumen percentage, average egg weight and weight loss of quail eggs. The results showed that increasing levels of calcium promoted after the storage period ( $\mathrm{P}$ $<0.05)$ better skin thickness, higher percentage of yolk, albumen and a lower percentage of increase in egg weight without significantly influence the weight percentage of bark and weight loss quail eggs after storage at room temperature for 14 days. It was concluded that the increasing levels of calcium in the diet was effective in maintaining the internal egg quality of Japanese quails after room temperature storage for 14 days.

Keywords: Coturnix coturnix japonica, storage, shell quality 
Rev. Bras. Saúde Prod. Anim., Salvador, v.16, n.1, p.139-148 jan./mar., 2015 http://www.rbspa.ufba.br ISSN 15199940

\section{INTRODUÇÃO}

A coturnicultura de postura tem se maximizado no Brasil em virtude de fatores como rápido crescimento, precocidade na produção e maturidade sexual (35 a 42 dias de idade), alta produtividade, longevidade em alta produção (14 a 18 meses), e rápido retorno financeiro (BARRETO et al., 2007). Segundo IBGE (2012), São Paulo é o maior produtor da região sudeste, com crescente oferta de ovos de codorna em conserva em bares e restaurantes.

Como todo produto de origem animal, os ovos de codorna perdem seu valor nutricional logo após a postura (FREITAS et al., 2011). Esta perda de qualidade é inevitável gerando perda de peso e redução da qualidade interna (BARBOSA et al. 2008). Diversos fatores podem afetar a qualidade interna tais como idade da ave, nutrição e temperatura de armazenamento. Durante a formação dos ovos o $\mathrm{CO}_{2}$ é dissolvido no albúmen e, após a postura, passa para o meio ambiente devido ao gradiente negativo de concentração osmótica, provocando aumento no $\mathrm{pH}$ (alcalinização) e fluidificação do albúmen que resultam em alteração no sabor e na palatabilidade do ovo. A fluidificação do albúmen é um processo bioquímico que se acelera com o aumento da temperatura e, somado a isso o ovo transpira e desidrata, e esses eventos podem variar em função do período de estocagem, temperatura ambiente, umidade relativa e porosidade da casca (POMBO et al., 2006; LEANDRO et al., 2005; MOURA et al., 2008).

A qualidade da casca é importante quando se trata de manutenção da qualidade interna dos ovos, pois ovos com casca mais espessa tendem a apresentar menor perda de $\mathrm{CO}_{2}$ e água, menor redução dos constituintes internos (albúmen e gema) e, por consequência, menor redução no seu peso. Este parâmetro pode ser afetado por fatores como a idade da ave (PAPAS et al., 2006). Aves mais velhas produzem ovos maiores (20\%) (MILES, 2000), porém, a quantidade de casca depositada não acompanha esse aumento, resultando em uma casca mais frágil, mais propensa a quebras e trincas (ITO et al., 2006). A inclusão de níveis crescentes de cálcio na dieta de poedeiras resulta em melhoria da espessura de casca, pois a cada inclusão de $1 \%$ de cálcio na dieta, ocorre melhora de $0,013 \mathrm{~mm}$ na espessura da casca (BARRETO et al., 2007; FREITAS et al., 2011). Este trabalho foi desenvolvido com o intuito de avaliar a influência de níveis crescentes de cálcio na dieta na melhoria da qualidade da casca e consequente manutenção da qualidade interna de ovos de codorna em final de produção, armazenados por 14 dias.

\section{MATERIAL E MÉTODOS}

O experimento foi realizado no setor de Avicultura da Universidade Federal Rural do Rio de Janeiro (UFRRJ) no período de março a maio de 2013, dividido em quatro períodos de 21 dias. Foram utilizadas 400 codornas japonesas com 46 a 58 semanas de idade. As aves foram alojadas em gaiolas de postura de arame galvanizado, onde foram distribuídas em um delineamento inteiramente casualizado onde foram testados cinco níveis de cálcio: $2,95 \%, 3,25 \%, 3,55 \%$, $3,85 \%, 4,15 \% \mathrm{Ca}$, com 10 repetições por tratamento com 8 codornas cada. A ração e a água foram fornecidas $a d$ libitum durante todo $\mathrm{o}$ período 
Rev. Bras. Saúde Prod. Anim., Salvador, v.16, n.1, p.139-148 jan./mar., 2015 http://www.rbspa.ufba.br ISSN 15199940

experimental e foram submetidas a um programa de luz de 16 horas diárias. As rações foram formuladas a base de milho e farelo de soja, de forma a atender as exigências mínimas nutricionais, segundo Rostagno (2011), exceto para cálcio (Tabela 1).

Tabela 1. Composição percentual e nutricional estimada das dietas experimentais

\begin{tabular}{|c|c|c|c|c|c|}
\hline \multirow{2}{*}{ Ingredientes } & \multicolumn{5}{|c|}{ Tratamentos } \\
\hline & $2,95 \%$ & $3,25 \%$ & $3,55 \%$ & $3,85 \%$ & $4,15 \%$ \\
\hline Milho moído & 49,635 & 49,635 & 49,635 & 49,635 & 49,635 \\
\hline Farelo de soja & 34,479 & 34,479 & 34,479 & 34,479 & 34,479 \\
\hline Calcário & 6,747 & 7,528 & 8,309 & 9,091 & 9,872 \\
\hline Óleo de soja & 3,671 & 3,671 & 3,671 & 3,671 & 3,671 \\
\hline Caulim & 3,400 & 2,600 & 1,800 & 1,000 & 0,200 \\
\hline Fosfato bicálcico & 1,066 & 1,066 & 1,066 & 1,066 & 1,066 \\
\hline DL-Metionina & 0,349 & 0,349 & 0,349 & 0,349 & 0,349 \\
\hline Sal comum & 0,325 & 0,325 & 0,325 & 0,325 & 0,325 \\
\hline L-Lisina HCL & 0,124 & 0,124 & 0,124 & 0,124 & 0,124 \\
\hline Sup. vitamínico & 0,100 & 0,100 & 0,100 & 0,100 & 0,100 \\
\hline Sup. mineral & 0,100 & 0,100 & 0,100 & 0,100 & 0,100 \\
\hline Total & 100,00 & 100,00 & 100,00 & 100,00 & 100,00 \\
\hline \multicolumn{6}{|l|}{ Composição nutricional estimada } \\
\hline Energia Metabolizável (Kcal/Kg) & 2800 & 2800 & 2800 & 2800 & 2800 \\
\hline Proteína Bruta $(\%)$ & 20,00 & 20,00 & 20,00 & 20,00 & 20,00 \\
\hline Cálcio $(\%)$ & 2,95 & 3,25 & 3,55 & 3,85 & 4,15 \\
\hline Fósforo Disponível (\%) & 0,303 & 0,303 & 0,303 & 0,303 & 0,303 \\
\hline Metionina + cistina Dig (\%) & 0,876 & 0,876 & 0,876 & 0,876 & 0,876 \\
\hline Metionina Dig (\%) & 0,606 & 0,606 & 0,606 & 0,606 & 0,606 \\
\hline Metionina Total (\%) & 0,632 & 0,632 & 0,632 & 0,632 & 0,632 \\
\hline Lisina Dig $(\%)$ & 1,077 & 1,077 & 1,077 & 1,077 & 1,077 \\
\hline Lisina Total (\%) & 1,174 & 1,174 & 1,174 & 1,174 & 1,174 \\
\hline
\end{tabular}

Composição por kg do produto1, 2:1Vitamina A (min) 7.500.000 UI/kg; vitamina D3 (min) 2.500 .000 $\mathrm{UI} / \mathrm{kg}$; vitamina E (min) $1.200 \mathrm{mg} / \mathrm{kg}$; vitamina $\mathrm{K} 3(\mathrm{~min}) 1.200 \mathrm{mg} / \mathrm{kg}$; tiamina (min) $1.500 \mathrm{mg} / \mathrm{kg}$; riboflavina (min) $5.500 \mathrm{mg} / \mathrm{kg}$; piridoxina $(\min ) 2000 \mathrm{mg} / \mathrm{kg}$; vitamina B12 (min) $12.000 \mathrm{mcg} / \mathrm{kg}$; niancina $35 \mathrm{~g} / \mathrm{kg}$; panteonato de cálcio (min) $10 \mathrm{~g} / \mathrm{kg}$; biotina (min) $67 \mathrm{mg} / \mathrm{kg}$; 202 Ferro (min) $60 \mathrm{~g} / \mathrm{kg}$; cobre (min) $13 \mathrm{~g} / \mathrm{kg}$; manganes (min) $120 \mathrm{~g} / \mathrm{kg}$; zinco (min) $100 \mathrm{~g} / \mathrm{kg}$; iodo (min) $2.500 \mathrm{mg} / \mathrm{kg}$; selênio (min) $500 \mathrm{mg} / \mathrm{kg}$.

Para cada avaliação, foram coletados vinte ovos de cada tratamento, por três dias consecutivos, totalizando assim 300 unidades avaliadas para cada intervalo de 21 dias. Os ovos frescos foram enviados para o laboratório de análise de produtos de origem animal da UFRRJ, pesados em balança de precisão de $0,01 \mathrm{~g}$ para o registro do peso fresco onde ficaram armazenados em temperatura ambiente (temperatura máxima de $31,4^{\circ} \mathrm{C}$; temperatura mínima de $21,8^{\circ} \mathrm{C} ; \mathrm{UR}=66 \%$ ), em embalagem de papelão aberta (Figura 1), por um período de 14 dias.

Os parâmetros avaliados foram: espessura de casca $(\mathrm{mm})$, peso da casca $(\mathrm{g})$, porcentagem de gema, porcentagem de albúmen, peso dos ovos (g) e perda de peso (\%). Após o período de armazenamento, os ovos foram novamente pesados em balança digital com precisão de 0,01g, obtendo-se assim o peso médio dos ovos após o armazenamento e a perda de peso foi obtida pela subtração desses pesos. Após a pesagem, os ovos foram 
Rev. Bras. Saúde Prod. Anim., Salvador, v.16, n.1, p.139-148 jan./mar., 2015 http://www.rbspa.ufba.br ISSN 15199940

quebrados, pesando-se albúmen e gema, separadamente em balança digital com precisão de $0,01 \mathrm{~g}$. A porcentagem de gema foi determinada dividindo-se o peso da gema pelo peso do ovo e o resultado multiplicado por 100 . A porcentagem de albúmen foi obtida dividindo-se o peso do albúmen pelo peso do ovo e o resultado multiplicado por 100. Para o parâmetro espessura, as cascas foram lavadas em água corrente, e secadas por 24 horas em temperatura ambiente (Figura 2). Após secagem, as cascas foram pesadas e quebradas em dois pontos na região equatorial onde foi realizada a medida da espessura por meio de um micrômetro analógico Mytutoyo (Figura 3), e efetuada a média das medidas obtidas.

Os resultados obtidos foram submetidos à análise de variância utilizando-se o Programa BioEstat e os efeitos foram estimados pelos modelos de regressão linear e quadrática, conforme o melhor ajustamento obtido para cada variável.

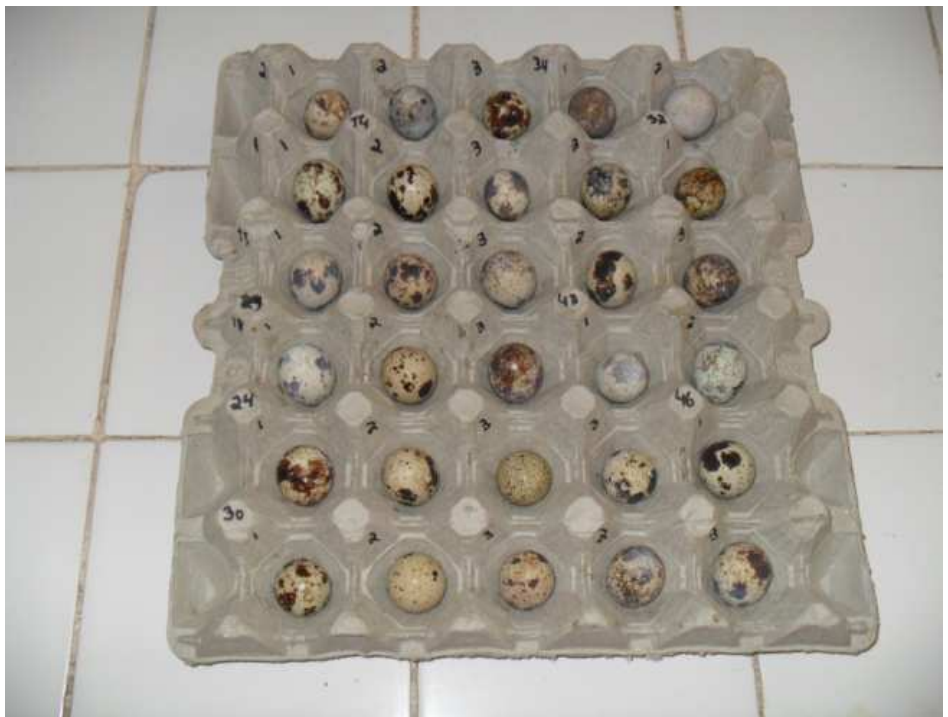

Figura 1. Embalagem de papelão para o armazenamento dos ovos

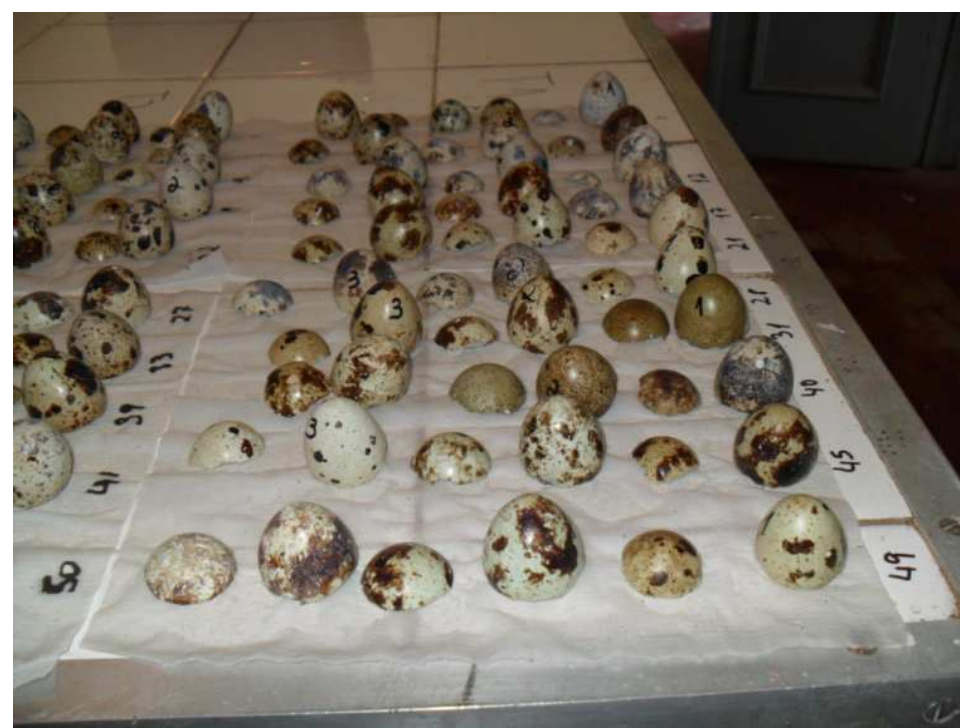

Figura 2. Secagem das cascas 


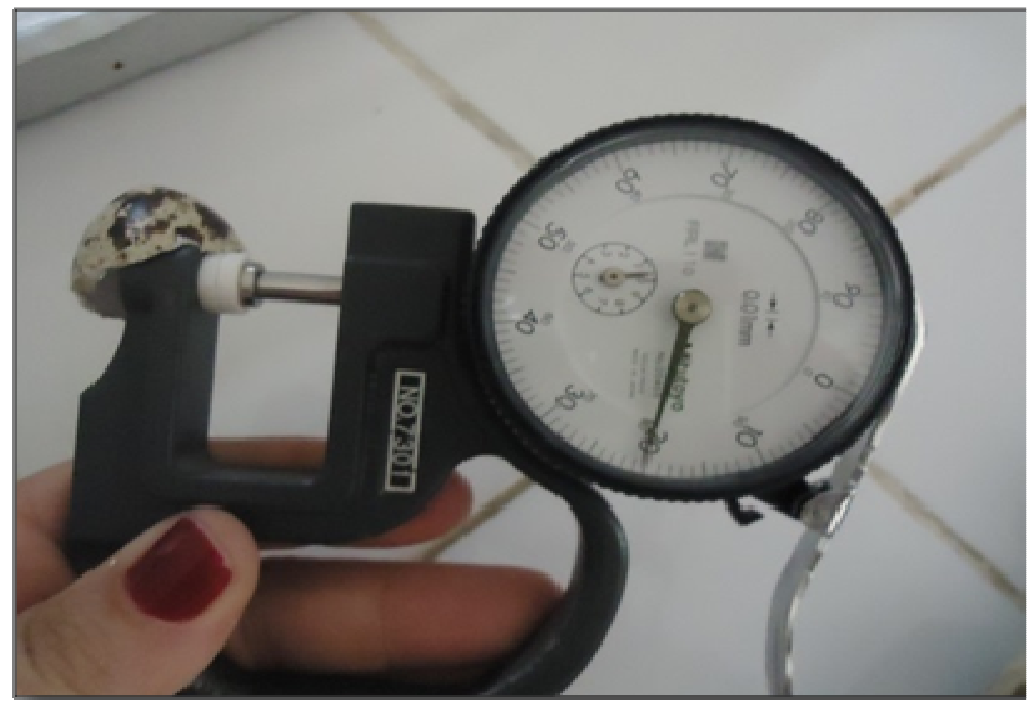

Figura 3. Determinação da espessura de casca

\section{RESULTADOS E DISCUSSÃO}

Os resultados referentes à espessura e porcentagem de casca, porcentagem de gema, porcentagem de albúmen e perda de peso de ovos de codornas japonesas alimentadas com diferentes níveis de cálcio armazenados por 14 dias estão apresentados na Tabela 2.

A espessura da casca dos ovos foi melhorando linearmente $\quad(\mathrm{P}<0,05)$ conforme foi se aumentando o nível de cálcio na dieta das codornas. Demonstrando comportamento expresso por uma função linear $(\mathrm{y}=0,1236+$ $\left.0,0230 x ; R^{2} 0,88\right)$ conforme os resultados da análise de regressão apresentados na Figura 4. As aves utilizadas no estudo se encontravam no final do primeiro ciclo de postura, e de acordo com Ito et al. (2006) em aves mais velhas ocorre uma redução na capacidade de retenção do cálcio proveniente da dieta, e quanto maior for o nível de cálcio maior será sua retenção e absorção pelo intestino, propiciando, portanto postura de ovos com cascas mais calcificadas (COSTA et al., 2010).

Tabela 2. Espessura, peso e porcentagem de casca, percentagem de gema, percentagem de albúmen, peso de ovos e perda de peso de ovos de codornas alimentadas com níveis crescentes de cálcio e armazenados por 14 dias

\begin{tabular}{lccccccc}
\hline \multirow{2}{*}{ Item } & \multicolumn{9}{c}{ Tratamentos (\%Ca) } & \multirow{2}{*}{ Regressão } & \multicolumn{2}{c}{ CV } \\
\cline { 2 - 6 } & $2,95 \%$ & $3,25 \%$ & $3,55 \%$ & $3,85 \%$ & $4,15 \%$ & & 2,54 \\
\hline Espessura casca $(\mathrm{mm})$ & 0,196 & 0,199 & 0,194 & 0,206 & 0,194 & $\mathrm{~L}$ & - \\
Peso casca $(\mathrm{g})$ & 0,923 & 0,956 & 0,926 & 0,971 & 0,952 & $\mathrm{~ns}$ & - \\
\% casca & 8,54 & 8,64 & 8,44 & 8,68 & 8,50 & $\mathrm{~ns}$ & 1,75 \\
\% gema & 35,37 & 35,69 & 36,53 & 36,82 & 36,61 & $\mathrm{~L}$ & 0,79 \\
\% albúmen & 56,09 & 55,67 & 55,03 & 54,50 & 54,89 & $\mathrm{~L}$ & 1,80 \\
Peso ovo (g) & 11,49 & 11,70 & 11,58 & 11,87 & 12,02 & $\mathrm{~L}$ & - \\
Perda de peso dos ovos $(\%)$ & 5,80 & 6,52 & 5,26 & 5,45 & 6,36 & $\mathrm{~ns}$ & - \\
\hline
\end{tabular}

$\mathrm{L}=$ significativo para regressão linear, $\mathrm{ns}=$ não significativo, $\mathrm{CV}=$ coeficiente de variação. 
Rev. Bras. Saúde Prod. Anim., Salvador, v.16, n.1, p.139-148 jan./mar., 2015 http://www.rbspa.ufba.br ISSN 15199940

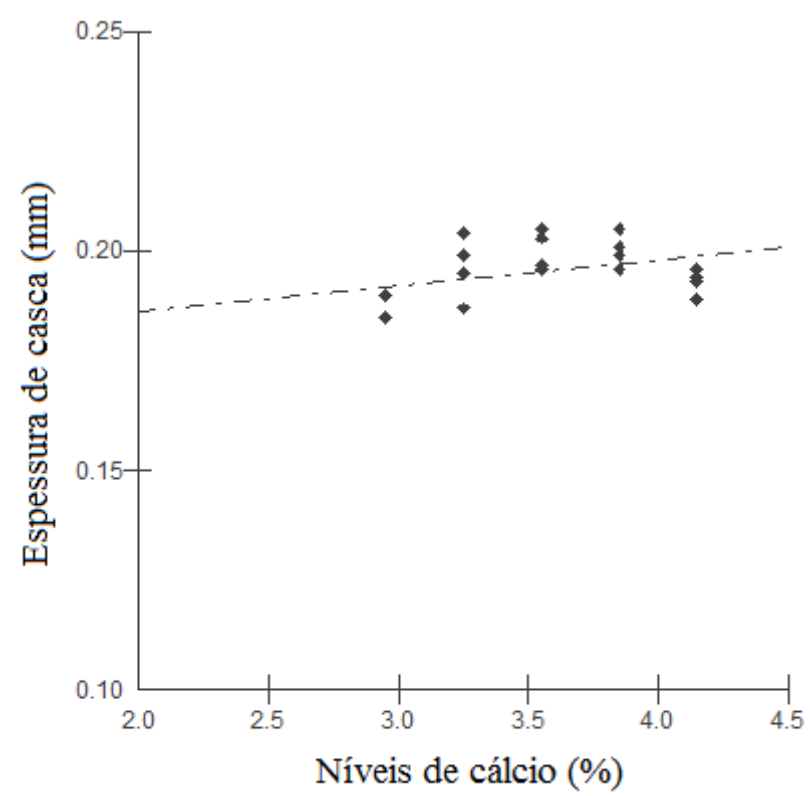

Figura 4. Espessura de casca de ovos de codornas alimentadas com níveis crescentes de cálcio e armazenados por 14 dias

O armazenamento não influenciou a espessura da casca, e estes resultados estão de acordo com os encontrados por Faria et al (2002) que verificando a influência do tempo de armazenamento na qualidade interna de ovos de galinhas poedeiras também não observaram o efeito do período de armazenamento sobre a espessura de casca. $\mathrm{O}$ peso e a porcentagem de casca dos ovos não sofreram influência significativa dos níveis de cálcio testados após o armazenamento de 14 dias.

A porcentagem de gema foi aumentando $(\mathrm{P}<0,05)$ após a inclusão de níveis crescentes de cálcio na dieta (Tabela 2), demonstrando efeito linear $(y=31,9478+$ $\left.1,2003 x ; R^{2} 0,81\right)$ na análise de regressão (Figura 5). Esse comportamento pode ser explicado pelas perdas de $\mathrm{CO} 2$ e água para o ambiente que promovem a fluidificação do albúmen e por consequência passagem de água do albúmen para a gema, aumentando assim sua proporção (LEANDRO et al., 2005; FREITAS et al., 2011).
A porcentagem de albúmen dos ovos armazenados foi diminuindo $(\mathrm{P}<0,05)$ após a inclusão de níveis crescentes de cálcio na dieta (Tabela 2), demonstrando efeito linear $(y=59,4605$ - 1,1900x; $\mathrm{R}^{2}$ 0,79) na análise de regressão (Figura 6). O comportamento da porcentagem de albúmen durante o armazenamento teve um efeito contrário ao da porcentagem de gema, pois são inversamente proporcionais, ou seja, conforme a porcentagem de gema aumenta a porcentagem de albúmen diminui (SILVA, 2011). De acordo com Faria et al. (2002) e Leandro et al. (2005), com o aumento do período de estocagem ocorre uma diminuição na porcentagem de albúmen, devido à perda de $\mathrm{CO}_{2}$ e água para o ambiente através dos poros da casca, sendo justificado também pelo resultado de percentagem de gema (Figura 5) que aumentou devido a passagem de água do albúmen para a gema. 
Rev. Bras. Saúde Prod. Anim., Salvador, v.16, n.1, p.139-148 jan./mar., 2015 http://www.rbspa.ufba.br ISSN 15199940

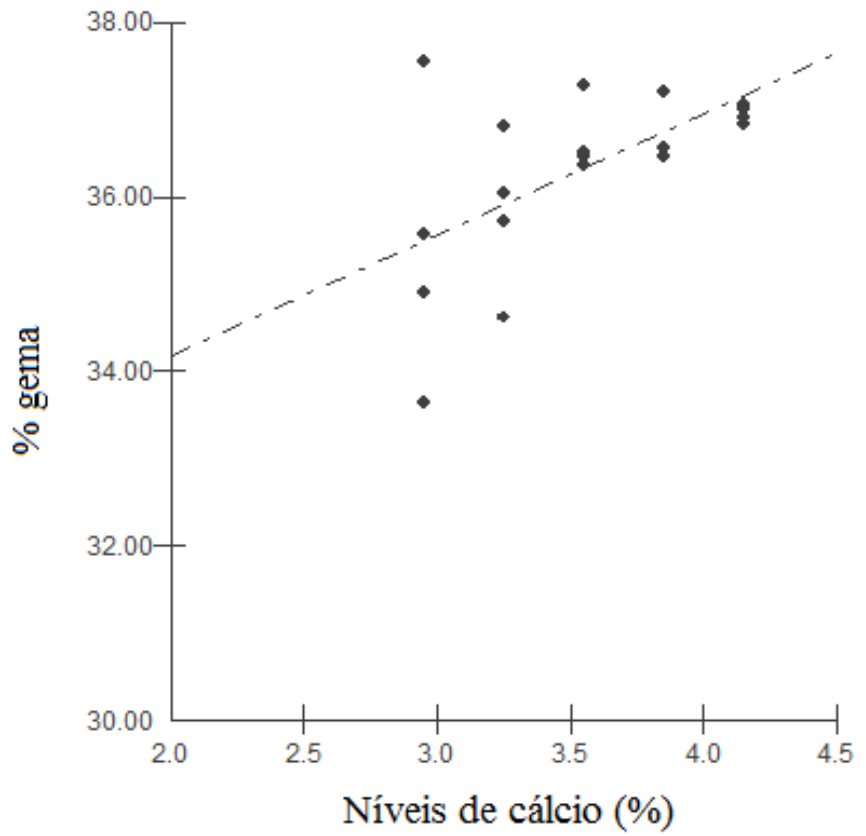

Figura 5. Porcentagem de gema de ovos de codornas alimentadas com níveis crescentes de cálcio e armazenados por 14 dias

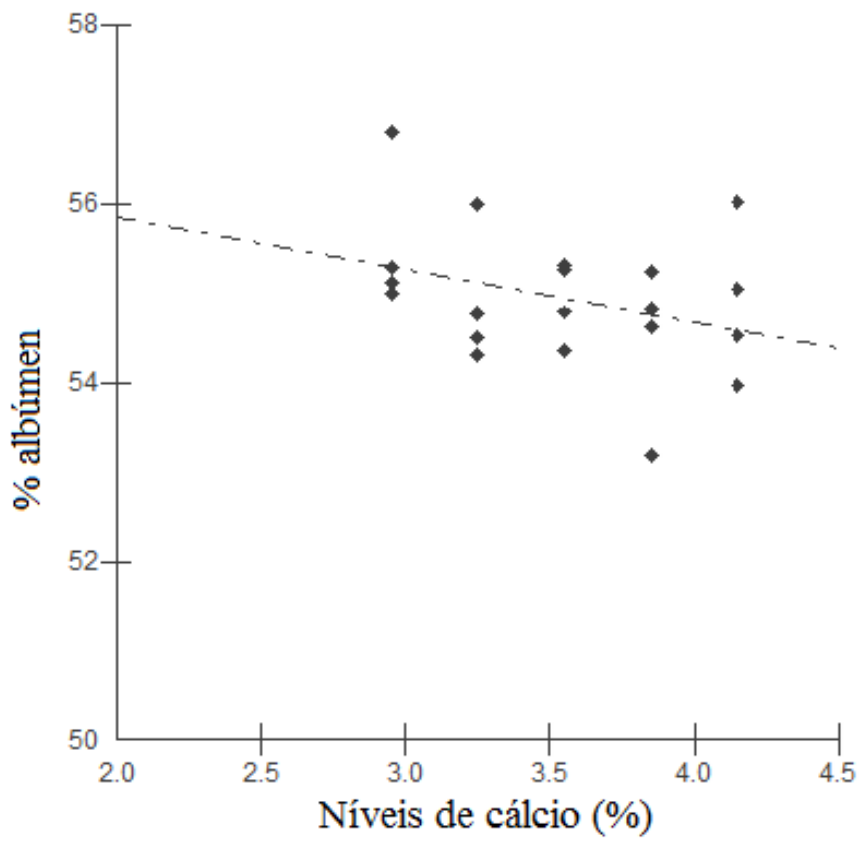

Figura 6. Porcentagem de albúmen de ovos de codornas alimentadas com níveis crescentes de cálcio e armazenados por 14 dias 
$\mathrm{O}$ peso de ovos armazenados foi melhorando $(\mathrm{P}<0,05)$ conforme se incluíam níveis crescentes de cálcio na dieta (Tabela 2), demonstrando efeito linear $\left(y=10,3080+0,4012 x ; R^{2} 0,81\right)$ na análise de regressão (Figura 4). Este parâmetro teve comportamento semelhante à espessura de casca (Figura 7). O peso dos ovos pode ser influenciado pela idade da ave, pela massa dos ovos, como por exemplo, quando ocorre redução da proporção de albúmen devido a desidratação, em função do período de estocagem dos ovos e também entre outros, pela nutrição da poedeira (PEDROSO et al., 1999; COSTA et al., 2007; BARRETO et al., 2007; FREITAS et. al., 2011).

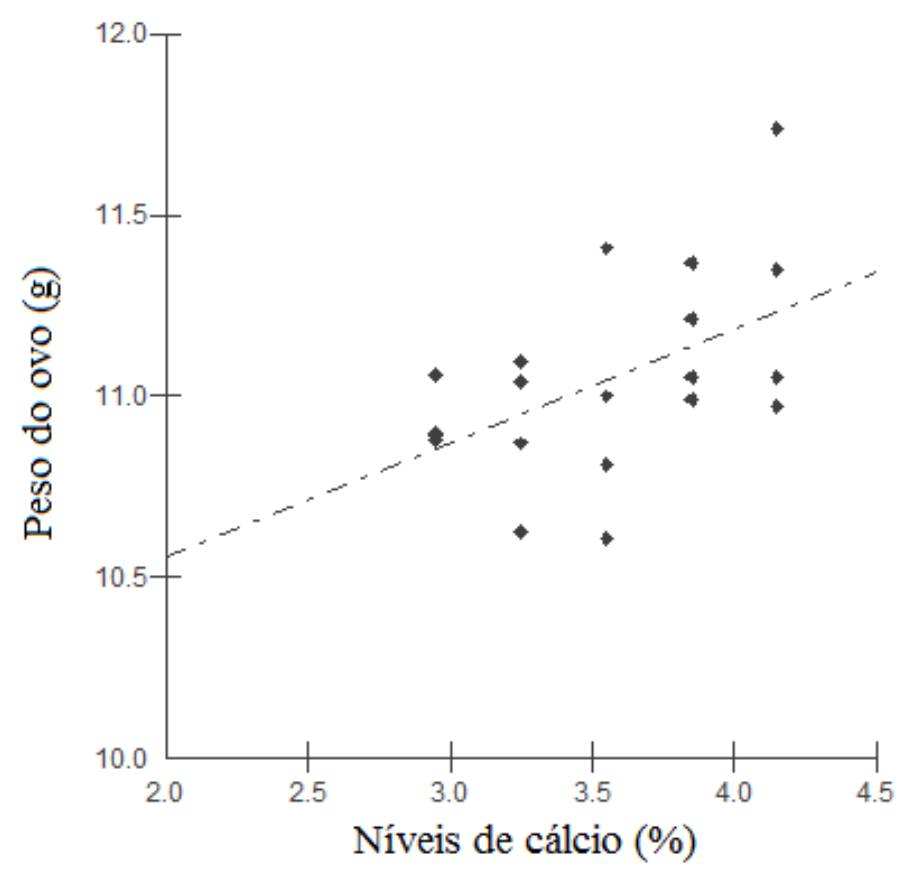

Figura 7. Peso de ovos (g) de codornas alimentadas com níveis crescentes de cálcio armazenados por 14 dias

Os níveis de cálcio estudados não foram o suficiente para influenciar na perda de peso dos ovos após o armazenamento.

A inclusão de níveis crescentes de cálcio na ração foi eficiente na manutenção da qualidade interna de ovos de codornas japonesas após o armazenamento em temperatura ambiente por 14 dias.

\section{REFERÊNCIAS}

BARBOSA, N.A.A.; SAKOMURA, N.K.; MENDONÇA, M.O.; FREITAS, E.R.; FERNANDES, J.B.K. Qualidade de ovos comerciais provenientes de poedeiras comerciais armazenados sob diferentes tempos e condições de ambiente. ARS Veterinária, v.24, n.2, p.127-133, 2008. 
Rev. Bras. Saúde Prod. Anim., Salvador, v.16, n.1, p.139-148 jan./mar., 2015 http://www.rbspa.ufba.br ISSN 15199940

BARRETO, S.L.T.; PEREIRA, C.A.; UMIGI, R.T.; ROCHA, T.C.; ARAUJO, M.S.; SILVA, C.S.; TORRES FILHO,

R.A. Determinação da exigência nutricional de cálcio de codornas japonesas na fase inicial do ciclo de produção. Revista Brasileira de Zootecnia, v.36, p.68-78, 2007.

COSTA, C.H.R.; BARRETO, S.L.T.; MOURA, W.C.O.; REIS, R.S.; LEITE, C.D.S.; MAIA, G.V.C. Níveis de fósforo e de cálcio em dietas para codornas japonesas em postura. Revista Brasileira de Zootecnia, v.36, n.6, p.2037-2046, 2007.

COSTA, C.H.R.; BARRETOS, S.L.T.; GOMES, P.C.; MAIA, G.V.C.; LIPARI, C.C.; HOSODA, L.H. Teores de cálcio em dietas para codornas japonesas no terço final de produção (45 a 57 semanas de idade). Arquivo Brasileiro de Medicina Veterinária e Zootecnia, v.62, n.5, p.1225-1231, 2010.

FARIA, L.V. de. Granulometria do calcário calcítico e níveis de cálcio para poedeiras comerciais em segundo ciclo de reprodução. 2002. 61p. Dissertação (Mestrado) - Universidade Federal de Lavras, Lavras.

FREITAS, L.W.; ALMEIDA PAZ, I.C.L.; GARCIA, R.G.; CALDARA, F.R., SENO, L.O.; FELIX, G.A.; LIMA, N.D.S.; FERREIRA, V.M.O.S.;

CAVICHIOLO, F. Aspectos qualitativos de ovos comerciais submetidos a diferentes condições de armazenamento. Revista Agrarian Dourados, v.4, n.11, p.66-72, 2011.

INSTITUTO BRASILEIRO DE GEOGRAFIA E ESTATÍSITCA IBGE. Sistema IBGE de recuperação automática. Estatística de produção pecuária, 2013. Disponível em <http:www.ibge.gov.br>. Acesso em: 15 dez. 2013.
ITO, D.T.; FARIA, D.E.; KUWANO, E.A.; JUNQUEIRA, O.M.; ARAUJO, L.F. Efeito do fracionamento de cálcio e granulometria de calcário sobre o desempenho e qualidade de ovos de poedeiras comerciais. Acta Scientiarum. Animal Science, v.28, n.2, p.187-195, 2006.

LEANDRO, N.S.M.; DEUS, H.AB.; STRINGHINI, J.H.; CAFÉ, M.B.; ANDRADE, M.A.; CARVALHO, F.B. Aspectos de qualidade interna e externa de ovos comercializados em diferentes estabelecimentos na região de Goiânia. Ciência Animal Brasileira, v.6, p.7178, 2005.

MILES, R. Fatores nutricionais relacionados à qualidade de casca dos ovos. In: SIMPÓSIO GOIANO DE AVICULTURA, 4., 2000. Goiânia. Anais... Goiânia, 2000. p.173-195.

MOURA, A.M.A.; OLIVEIRA, N.T.E.; THIEBAUT, J.T.L.; MELO, T.V. Efeito da temperatura de estocagem e do tipo de embalagem sobre a qualidade interna de ovos de codornas japonesas (Coturnix japonica).Ciência agrotécnica, v.32, n.2, p. 578-583, 2008.

PAPPAS, A.C.; ACAMOVIC, T. SPARKS, N.H.C.; SURAI, P.F.; McDEVITT, R.M. Effects of supplementing broiler breeder diets with organoselenium compounds and polyusatured fatty acids on hatchability. Poultry Science, v.85, p.1584-1593, 2006.

PEDROSO, A.A.; MORAES, V.M.B.; ARIKI, J.; KRONKA, S.N. Efeitos de níveis dietéticos de cálcio e fósforo disponível sobre o desempenho e qualidade dos ovos de codornas japonesas. ARS Veterinária, v.15, n.2, p.135-139, 1999. 
Rev. Bras. Saúde Prod. Anim., Salvador, v.16, n.1, p.139-148 jan./mar., 2015 http://www.rbspa.ufba.br

POMBO, C.R.; MANO, S.B.;

OLIVEIRA, V.M.; CARVALHO,

J.C.A.P; KASNOWSKI, M.C.;

SAMPAIO FILHO, E. Efeito do

termoprocessamento sobre o peso e a

qualidade interna de ovos inteiros.

Revista Brasileira de Ciência

Veterinária, v.13, n.3, p.183-185,

2006.

ROSTAGNO, H.S; ALBINO, L.F.T;

DONZELE, J.L; GOMES, P.C;

OLIVEIRA, R.F. de; LOPES, D.C;

FERREIRA, A.S; BARRETO, S.L. de

$T$. Tabelas brasileiras para aves $\mathrm{e}$

suínos: composição de alimentos e exigências nutricionais. 3.ed. Viçosa, MG: Universidade Federal de Lavras, 2011. 252p.

SILVA, A.P. Níveis de cálcio e fósforo na dieta de codornas japonesas (Coturnix coturnix japonica) em diferentes fases do ciclo de produção e seus efeitos sobre desempenho produtivo e qualidade de ovos. 2011. 47p. Dissertação (Mestrado). Faculdade de Medicina Veterinária e Zootecnia Universidade Estadual Paulista, Botucatu.

Data de recebimento: 11/08/2014

Data de aprovação: 25/02/2015 